\title{
Communication \\ Efficient Palladium-Catalyzed Synthesis of 2-Aryl Propionic Acids
}

\author{
Helfried Neumann ${ }^{1}\left(\mathbb{D}\right.$, Alexey G. Sergeev $\left.{ }^{2} \mathbb{(}\right)$, Anke Spannenberg ${ }^{1}$ and Matthias Beller ${ }^{1, *(\mathbb{D})}$ \\ 1 Leibniz-Institut für Katalyse e.V., Albert-Einstein-Straße 29a, 18059 Rostock, Germany; \\ Helfried.Neumann@catalysis.de (H.N.); Anke.Spannenberg@catalysis.de (A.S.) \\ 2 Department of Chemistry, University of Liverpool, Liverpool L69 7ZD, UK; A.Sergeev@liverpool.ac.uk \\ * Correspondence: Matthias.Beller@catalysis.de
}

Academic Editor: José Pérez Sestelo

Received: 2 July 2020; Accepted: 24 July 2020; Published: 28 July 2020

check for updates

\begin{abstract}
A flexible two-step, one-pot procedure was developed to synthesize 2-aryl propionic acids including the anti-inflammatory drugs naproxen and flurbiprofen. Optimal results were obtained in the presence of the novel ligand neoisopinocampheyldiphenylphosphine (NISPCPP) (9) which enabled the efficient sequential palladium-catalyzed Heck coupling of aryl bromides with ethylene and hydroxycarbonylation of the resulting styrenes to 2-aryl propionic acids. This cascade transformation leads with high regioselectivity to the desired products in good yields and avoids the need for additional purification steps.
\end{abstract}

Keywords: Heck reaction; styrene; methoxycarbonylation; profene; palladium

\section{Introduction}

2-Aryl propionic acids, such as ibuprofen, ketoprofen, naproxen, and flurbiprofen, belong to an important class of non-steroidal anti-inflammatory drugs (NSAIDs) which are extensively used in the treatment of inflammatory diseases and for the relief of pain [1]. Among the numerous known synthetic methods for their preparation [2,3], the regioselective carbonylation of styrenes provides straightforward and easy access [4]. Although notable progress has been reported in the enantioselective hydroxycarbonylation of styrenes [5-7], still, the racemic hydroxy/alkoxy-carbonylation continues to be attractive for the scientific community, too. Here, palladium complexes in the presence of acid represent state-of-the-art catalyst systems for the synthesis of 2-aryl propionic acid. Recent catalyst developments in this area include the preparation of heterogeneous Pd-TPPTS complexes supported onto acidic resins [8] as well as homogenous systems such as-PdCl(allyl)(tri-oxo-adamantyl cage phosphines) [9], water-soluble Pd-TPPTS complexes [10], palladium(II) complexes containing naphthyl(diphenyl)-phosphine ligands [11] or bulky bidentate phosphines [12], and $\mathrm{PdCl}_{2}\left(\mathrm{PPh}_{3}\right)_{2} / \mathrm{HCl} / \mathrm{CO} / \mathrm{THF}$ in combination with heteropolyacids [13].

Some years ago, our group reported a two-step protocol for the synthesis of ketoprofen and suprofen. These two drugs were synthesized following a tandem carbonylative Suzuki coupling and subsequent hydroxycarbonylation [14]. Inspired by this previous work and our interest in carbonylation reactions [15], here we describe a more flexible two-step, one-pot procedure for the synthesis of diverse 2-aryl propionic acids. Specifically, we utilized the palladium-catalyzed Heck reaction with aryl bromides and ethylene to give the corresponding styrene derivatives $[16,17]$ which are directly hydroxycarbonylated to the desired 2-aryl propionic acids without changing the palladium catalyst.

\section{Results and Discussion}

In preliminary experiments, we optimized the Heck reaction of 4-bromoanisole 1a and ethylene to yield 4-methoxystyrene 2 a. Optimal results (90\% yield) were obtained using a mixture of 
$\mathrm{Pd}(\mathrm{OAc})_{2} / \mathrm{BuPAd}_{2}$ [18] (0.5 mol\%/2.0 mol\%) in the presence of $1.5 \mathrm{eq} \mathrm{NEt}_{3}$ and 20 bar ethylene. To directly perform the carbonylation step, the reaction solution was acidified with $0.5 \mathrm{mmol} \mathrm{HCl}$ and the autoclave was pressurized with 40 bar CO yielding in total $72 \%$ of 2-(4-anisyl) propionic acid 3a along with $6 \%$ of the linear isomer $4 \mathbf{a}$ (Table 1, entry 1 ). Because of the good water solubility and its boiling point, dioxane was identified as the best solvent. To improve the selectivity for the desired branched carboxylic acid and to facilitate the final purification, the influence of phosphine ligands was evaluated (Table 1). Interestingly, in the presence of some of the ligands (e.g., $\mathrm{P}(\mathrm{o}-\mathrm{tolyl})_{3}$ and Johnphos), only the Heck reaction occurred and no carbonylation process was observed (Table 1, entries 2 and 3). On the other hand, ligands 1,1'-bis(diphenylphosphino)ferrocene (DPPF), $\mathrm{P}(\mathrm{t}-\mathrm{Bu})_{3}, \mathrm{t}-\mathrm{Bu}-\mathrm{XPhos}$, and 2-diadamantyl- phosphino-(2,6-diisopropylphenyl)-1H-imidazole allowed for both catalytic steps but gave somewhat lower product yields of $55 \%, 70 \%, 65 \%$, and 33\%, respectively (Table 1, entries 4-7).

Table 1. Palladium-catalyzed two-step synthesis for 2-aryl propionic acid 3a.

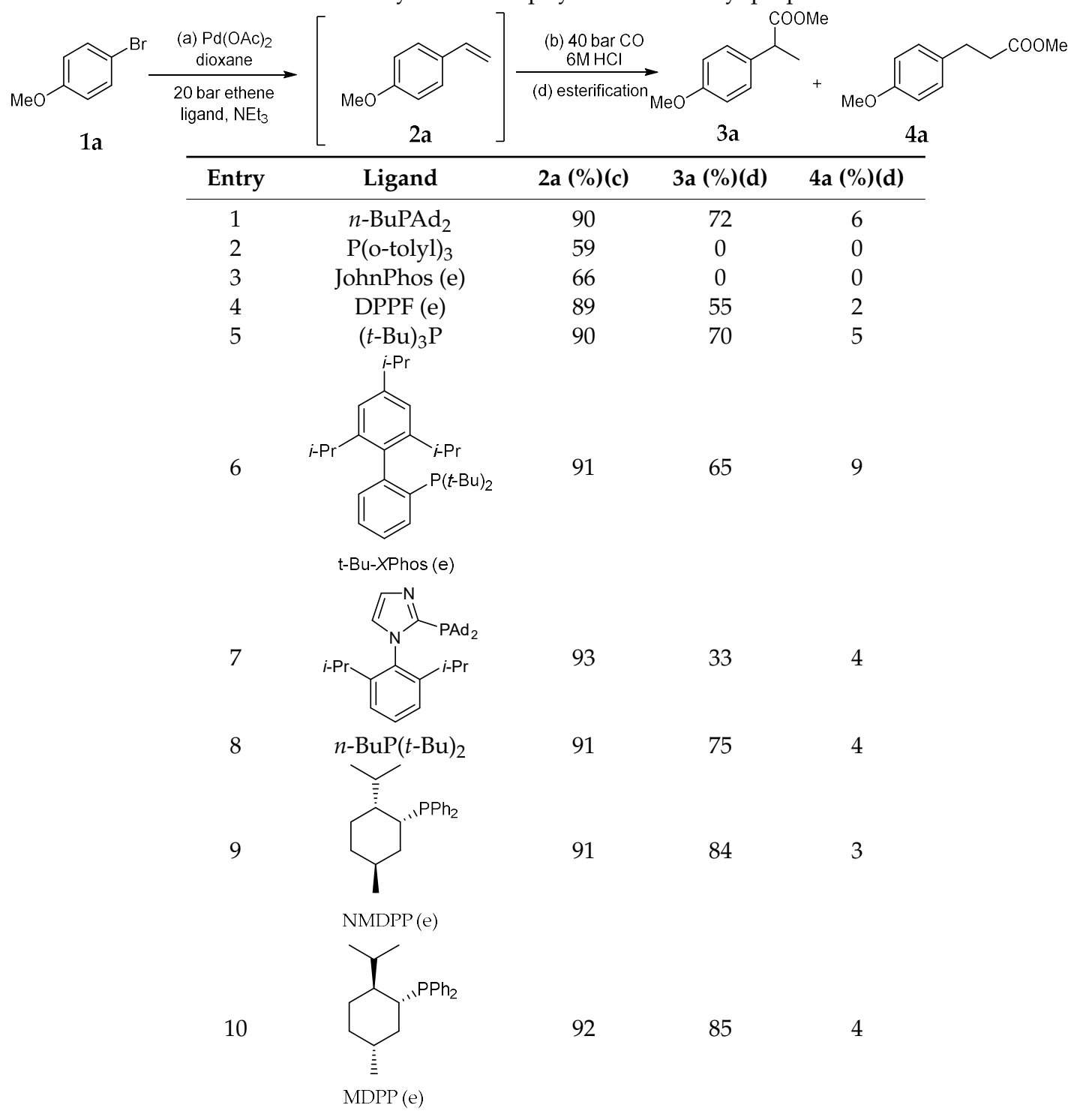

(a) First step: $\mathrm{Pd}(\mathrm{OAc})_{2}(0.5 \mathrm{~mol} \%)$, ligand $(2.0 \mathrm{~mol} \%)$, dioxane $(2 \mathrm{~mL}), \mathrm{NEt}_{3}\left(1.5 \mathrm{mmol}^{2}, 4\right.$-bromoanisole $(1 \mathrm{mmol})$, ethene $(20 \mathrm{bar}), 0.2 \mathrm{eq}$ hexadecane $120{ }^{\circ} \mathrm{C}, 20 \mathrm{~h}$; (b) second step: $83 \mu \mathrm{L} \mathrm{HCl}(6 \mathrm{M}), \mathrm{CO}(40 \mathrm{bar})$, $100{ }^{\circ} \mathrm{C}, 20 \mathrm{~h}$; (c) a sample of the first half reaction was submitted to the GC to determine the yield of styrenes; (d) a sample was esterified with $\mathrm{MeOH}$ and trimethylsilyl diazomethane to determine the overall yield by GC; (e) JohnPhos ((2-biphenyl)di-tert-butyl-phosphine), DPPF (1,1'-bis(diphenylphosphino)ferrocene), t-Bu-XPhos (2-di-tert-butylphosphino-2' $4^{\prime}, 6^{\prime}$-triisopropylbiphenyl), NMDPP (neomenthyldiphenylphosphine), MDPP (menthyldi-phenylphosphine). 
Inspired by some original investigations of Chiusoli and co-workers [19] and a patent application [20], which described the palladium-catalyzed methoxycarbonylation of styrenes using a neomenthyldiphenylphosphine ligand (NMDPP), we also tested the commercially available NMDPP ligand in our one-pot, two-step reaction (Table 1, entry 9). To our delight, 4-methoxystyrene was obtained with a $91 \%$ yield, and the following carbonylation gave an overall yield of $84 \%$ of 2-(4-anisyl) propionic acid with only $3 \%$ of the undesired linear aryl propionic acid. Similar results were obtained in the presence of a menthyldiphenylphosphine ligand (MDPP) [21] (Table 1, entry 10).

Based on these results, we synthesized related terpene-based ligands isopinocampheyldiphenylphosphine (ISPCDPP) (7) and neoisopinocampheyldiphenylphosphine (NISPCDPP) (9) according to the route shown in Scheme 1.

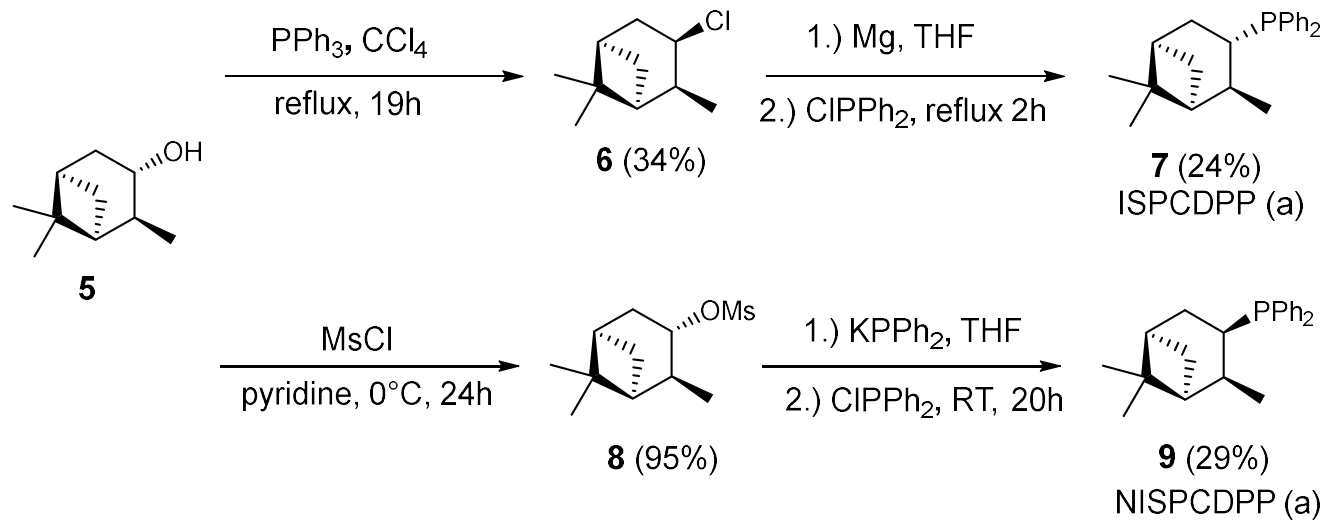

Scheme 1. Synthesis of the ligands isopinocampheyldiphenylphosphine (ISPCDPP) (7) and neoisopinocampheyldiphenylphosphine (NISPCDPP) (9). (a) For purification, the ligands were converted to the corresponding borane adduct.

The synthesis of the novel ligand isopinocampheyldiphenylphosphine ISPCDPP (7) started from commercially available (+)isopinocampheol (5) which was converted to isopinocampheyl chloride (6) with inversion at the reacting stereocenter [22] Next, conversion of (6) into the Grignard and subsequent quenching with diphenylchlorophosphine gave rise to ISPCDPP (7). With regard to the synthesis of NISPCDPP (9), (+)isopinocampheol (5) was treated with mesyl chloride in pyridine to give isopinocampheol methansulfonate (8) [23]. Subsequent nucleophilic substitution with potassium diphenylphosphide occurred with inversion of configuration to yield the novel ligand neoisopinocampheyldiphenylphosphine NISPCDPP (9). The ligand structure was confirmed by X-ray analysis (Figure 1). See details in Supplementary Materials.

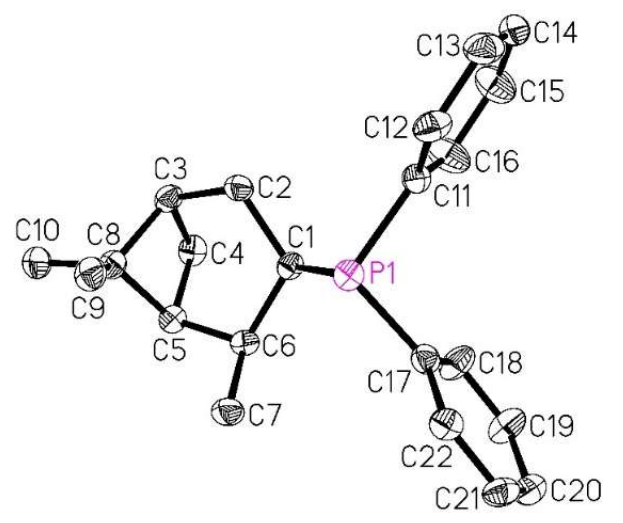

Figure 1. Molecular structure of NISPCDPP (9) in the crystal. Hydrogen atoms are omitted for clarity. Displacement ellipsoids correspond to $30 \%$ probability [24]. 
Catalytic experiments revealed the best yield of 3a (89\%) in the presence of NISPCDPP (9) (Table 2, entries 1). Hence, this ligand was used in all following experiments. In general, the palladium-catalyzed one-pot, two-step procedure can be used to prepare a variety of 2-aryl propionic acids in good to very good overall yields in the presence of the NISPCDPP/Pd(OAc) $)_{2}$ system. Both the Heck reaction and the carbonylation step proceeded with high chemo- and regioselectivity. Since the optimal reaction conditions were developed using electron-rich anisole as substrate, other electron-rich substrates showed good results, too. Exemplarily, methyl- and t-butyl-substituted aryl bromides gave $74 \%$ and $85 \%$ yield of the corresponding methyl 2-arylpropionate (Table 2, entries 2 and 3). Nevertheless, this cascade process also tolerates electron-withdrawing substituents, such as chloride, fluoride, trifluoromethyl, and cyano giving, $75 \%, 77 \%, 84 \%, 72 \%$, and $68 \%$ yield, respectively (Table 2 , entries 4-8). Notably, the reaction of 1-bromo-3-fluoro-4-phenyl-benzene 1i gave the desired 2-aryl propionic acid which is a known drug under the brand name Flurbiprofen ${ }^{\circledR}$ in $77 \%$ yield (Table 2, entry 9). Finally, one of the most important NSAIDs Naproxen ${ }^{\circledR}$ was prepared in a similar fashion in $60 \%$ overall yield (Table 2, entry 10).

Table 2. Palladium-catalyzed two-step, one-pot reaction to profenes.

\begin{tabular}{|c|c|c|c|c|}
\hline$\#=\mathrm{a}$ & & & & \\
\hline Entry & Aryl Bromide & Styrene (c) & $\begin{array}{c}\text { Yield }(\%)(d) \\
\text { Methyl 2-aryl Propionate }\end{array}$ & $\begin{array}{c}\text { Yield }(\%)(d) \\
\text { Methyl 3-aryl Propionate }\end{array}$ \\
\hline $1(\mathrm{f})$ & & $2 a(90 \%)$ & $3 \mathbf{a}(89,55 \%)$ & $4 \mathbf{a}(1 \%)$ \\
\hline 2 & & $2 \mathbf{b}(75 \%)$ & $3 \mathbf{b}(74,70 \%)$ & $4 \mathbf{b}(1 \%)$ \\
\hline 3 & & 2c $(87 \%)$ & $3 c(85,60 \% \%)$ & $4 \mathrm{c}(1 \%)$ \\
\hline 4 & & $2 d(80 \%)$ & $3 d(75,21 \%)(e)$ & $4 d(3 \%)$ \\
\hline 5 & & $2 e(79 \%)$ & $3 \mathbf{e}(77,36 \%)(\mathrm{e})$ & $4 \mathbf{e}(1 \%)$ \\
\hline 6 & & $2 f(85 \%)$ & $3 f(84,54 \%)$ & $4 f(1 \%)$ \\
\hline 7 & & $2 g(87 \%)$ & $3 \mathbf{g}(72,55 \%)$ & $4 \mathbf{g}(3 \%)$ \\
\hline 8 & & $2 \mathrm{~h}(79 \%)$ & $3 h(68,54 \%)$ & $4 h(4 \%)$ \\
\hline
\end{tabular}


Table 2. Cont.

\begin{tabular}{|c|c|c|c|c|}
\hline Entry & Aryl Bromide & Styrene (c) & $\begin{array}{c}\text { Yield }(\%)(\mathrm{d}) \\
\text { Methyl 2-aryl Propionate }\end{array}$ & $\begin{array}{c}\text { Yield }(\%)(\mathrm{d}) \\
\text { Methyl 3-aryl Propionate }\end{array}$ \\
\hline 9 & & $2 \mathbf{i}(79 \%)$ & $3 \mathbf{i}(77,74 \%)$ & $4 \mathbf{i}(2 \%)$ \\
\hline 10 & & $2 \mathbf{j}(70 \%)$ & $3 \mathbf{j}(60,36 \%)(e)$ & $4 \mathbf{j}(2 \%)$ \\
\hline
\end{tabular}

(a) First step: $\mathrm{Pd}(\mathrm{OAc})_{2}(0.75 \mathrm{~mol} \%)$, NISPCDPP (9) (3.0 mol\%), dioxane (2 $\left.\mathrm{mL}\right), \mathrm{NEt}_{3}(1.5 \mathrm{mmol})$, aryl bromide $(1 \mathrm{mmol})$, ethene (20 bar), 0.2 eq hexadecane, $120^{\circ} \mathrm{C}, 20 \mathrm{~h}$; (b) second step: $83 \mu \mathrm{L} \mathrm{HCl}(6 \mathrm{M}), \mathrm{CO}(40 \mathrm{bar}), 100{ }^{\circ} \mathrm{C}, 20 \mathrm{~h}$; (c) a sample of the first half reaction was submitted to the GC to determine the yield of styrenes; (d) a sample was esterified with $\mathrm{MeOH}$ and trimethylsilyl diazomethane to determine the overall yield by $\mathrm{GC}$ analysis, (GC/isolated yield\%); (e) the difference in GC yield and isolated yield is caused by a non-complete esterification with $\mathrm{H}_{2} \mathrm{SO}_{4} / \mathrm{MeOH}$ or in taking several samples for GC analysis; (f) usage of ligand ISPCDPP (7) gives $\mathbf{2 a}$, 3a, and $\mathbf{4 a}$ in $90 \%, 86 \%$, and $1 \%$ yield, respectively.

\section{Conclusions}

In conclusion, we developed a general and convenient two-step, one-pot protocol for the synthesis of 2-aryl propionic acids. Following our protocol, the anti-inflammatory drugs naproxen and flurbiprofen are easily accessible. Key steps of this process are the Heck reaction of ethylene with different substituted aryl bromides and a subsequent hydroxycarbonylation. Notably, both steps proceed in the presence of the same catalyst giving the desired products in $60-85 \%$ overall yield.

Supplementary Materials: The following are available online at http://www.mdpi.com/1420-3049/25/15/3421/s1, Experimental and crystallographic details for (9).

Author Contributions: H.N. carried out the screening experiments and the scope. A.G.S. synthesized for the first time the ligands ISPCDPP (7) and NISPCDPP (9) shown in the Scheme 1. A.S. performed the X-ray crystal structure analysis shown in Figure 1. H.N. and M.B. developed the project and wrote the manuscript. All authors have read and agreed to the published version of the manuscript.

Funding: This research was funded by State of Mecklenburg-Western Pommerania and the Federal State of Germany (BMBF).

Acknowledgments: We gratefully thank the analytical department for measuring samples and Sandra Leiminger and Andreas Koch for technical support.

Conflicts of Interest: The authors declare no conflicts of interest.

\section{References}

1. Wongrakpanich, S.; Wongrakpanich, A.; Melhado, K.; Rangaswami, J. A comprehensive review of non-steroidal anti-inflammatory drug use in the elderly. Aging Dis. 2018, 9, 143-150. [CrossRef] [PubMed]

2. Stahly, G.P.; Starrett, R.M. Production methods for chiral non-steroidal anti-inflammatory profene drugs. Chirality Ind. II 1997, 19-40.

3. Rieu, J.-P.; Boucherle, A.; Cousse, H.; Mouzin, G. Methods for the synthesis of anti-inflammatory 2-aryl propionic acids. Tetrahedron 1986, 42, 4095-4131. [CrossRef]

4. Del Rio, I.; Claver, C.; van Leeuwen, P.W. On the mechanism of hydroxycarbonylation of styrene with palladium systems. Rev. Eur. J. Inorg. Chem. 2001, 11, 2719-2738. [CrossRef]

5. Li, J.; Ren, W.; Daia, J.; Shi, Y. Palladium-catalyzed regio- and enantioselectivehydroesterification of aryl olefins with CO gas. Org. Chem. Front. 2018, 5, 75-79. [CrossRef]

6. Harkness, G.J.; Clarke, M.L. A highly enantioselective alkene methoxycarbonylation enables a concise synthesis of (S)-flurbiprofen. Eur. J. Org. Chem. 2017, 4859-4863. [CrossRef] 
7. Konrad, T.M.; Durrani, J.T.; Cobley, C.J.; Clarke, M.L. Simultaneous control of regioselectivity and enantioselectivity in the hydroxycarbonylation and methoxycarbonylation of vinyl arenes. Chem. Commun. 2013, 49, 3306-3308. [CrossRef]

8. He, Z.; Hou, Z.; Zhang, Y.; Wang, T.; Dilixiati, Y.; Eli, W. Hydrocarboxylation of olefins by supported aqueous-phase catalysis. Catal. Today 2015, 247, 147-154. [CrossRef]

9. Fuentes, J.A.; Slawin, A.M.Z.; Clarke, M.L. Application of palladium (trioxo-adamantyl cage phosphine)chloride complexes as catalysts for the alkoxycarbonylation of styrene. Catal. Sci. Technol. 2012, 2, 715-718. [CrossRef]

10. He, Z.; Hou, Z.; Luo, Y.; Zhou, L.; Liu, Y.; Eli, W. Effects of alkali halide salts on hydrocarboxylation of styrene catalyzed by water-soluble palladium phosphine complexes. Catal. Lett. 2013, 143, 289-297. [CrossRef]

11. Zolezzia, S.; Moyab, S.A.; Valdebenitoa, G.; Abarcaa, G.; Paradaa, J.; Aguirre, P. Methoxycarbonylation of olefins catalyzed by palladium(II) complexes containing naphthyl (diphenyl)phosphine ligands. Appl. Organometal. Chem. 2014, 28, 364-371. [CrossRef]

12. Frew, J.J.R.; Damian, K.; Van Rensburg, H.; Slawin, A.M.Z.; Tooze, R.P.; Clarke, M.L. Palladium(II) complexes of new bulky bidentate phosphanes: Active and highly regioselective catalysts for the hydroxycarbonylation of styrene. Chem. Eur. J. 2009, 15, 10504-10513. [CrossRef] [PubMed]

13. Ali, B.E. Effect of heteropolyacids on the hydroxycarbonylation of styrene. React. Kinet. Catal. Lett. 2002, 77, 227-236. [CrossRef]

14. Neumann, H.; Brennführer, A.; Beller, M. An efficient and practical sequential one-pot synthesis of suprofen, ketoprofen and other 2-arylpropionic acids. Adv. Synth. Catal. 2008, 350, 2437-2442. [CrossRef]

15. Dong, K.; Fang, X.; Gülak, S.; Franke, R.; Spannenberg, A.; Neumann, H.; Jackstell, R.; Beller, M. Highly active and efficient catalysts for alkoxycarbonylation of alkenes. Nat. Commun. 2017, 8, 14117-14123. [CrossRef] [PubMed]

16. DeVries, R.A.; Mendoza, A. Synthesis of high-purity o- and p-vinyltoluenes by the heck palladium-catalyzed arylation reaction. Organometallics 1994, 13, 2405-2411. [CrossRef]

17. Smith, C.R.; RajanBabu, T.V. Low pressure vinylation of aryl and vinyl halides via Heck-Mizoroki reactions using ethylene. Tetrahedron 2010, 66, 1102-1110. [CrossRef]

18. Klaus, S.; Neumann, H.; Zapf, A.; Strübing, D.; Hübner, S.; Almena, J.; Riermeier, T.; Groß, P.; Sarich, M.; Krahnert, W.-R.; et al. A general and efficient method for the formylation of aryl and heteroaryl bromides. Angew. Chem. Int. Ed. 2006, 45, 154-158. [CrossRef]

19. Cometti, G.; Chiusoli, G.P. Asymmetric induction in carbomethoxylation of vinylaromatics. J. Organomet. Chem. 1982, 236, C31. [CrossRef]

20. Albemarle Corporation [US/US]. Preparation of Carboxylic Compounds and Their Derivatives. WO Patent 00/02840, 20 January 2000.

21. Tanaka, M.; Ogata, I.A. Novel route to menthyldiphenylphosphinediphenyl. Bull. Chem. Soc. Jpn. 1975, 48, 1094. [CrossRef]

22. Scianowski, J.; Rafinski, Z.; Wojtczak, A. Syntheses and reactions of new optically active terpene dialkyl diselenides. Eur. J. Org. Chem. 2006, 3216-3225. [CrossRef]

23. Chloupek, F.J.; Zweifel, G. Solvolysis of iso- and neoisopinocampheyl sulfonate esters. stereochemical considerations. J. Org. Chem. 1964, 29, 2092-2093. [CrossRef]

24. CCDC 2009413 Contains the Supplementary Crystallographic Data for This Paper. These Data Are Provided Free of Charge by the Joint Cambridge Crystallographic Data Centre and Fachinformationszentrum Karlsruhe Access Structures Service. Available online: www.ccdc.cam.ac.uk/structures (accessed on 12 June 2020).

(C) 2020 by the authors. Licensee MDPI, Basel, Switzerland. This article is an open access article distributed under the terms and conditions of the Creative Commons Attribution (CC BY) license (http://creativecommons.org/licenses/by/4.0/). 